\title{
Reflective Mediation: Toward a Sociocultural Conception of Situated Reflection
}

\author{
Christian Dalsgaard
}

Aarhus University, Denmark

Article received 15 January 2019 / Article revised 25 September / Accepted 22 January / Available online 7 February 2020

\begin{abstract}
The objective of the article is to contribute to the development of a sociocultural conception of situated reflection that can be used in empirical studies of reflection, and that can be utilised in development of educational practices. Based on a development of the concept of 'reflective mediation', a conception of reflection is developed from a situated understanding of learning processes. Taking a situated approach, the concept of reflective mediation describes how to understand reflection as an integral part of the immediate activities of the individual. A theoretical framework is developed for empirical studies on reflective activities of higher education students. The framework can be utilised by teachers to develop teaching methods in support of reflection in student learning. The concept of reflective mediation is developed from a combination of pragmatism and cultural historical activity theory, and it covers seven categories of learning and reflection processes. The article makes a distinction between three forms of mediation, two forms of empirical reflection, and two forms of theoretical reflection. The article concludes in a discussion of the implications of the theoretical framework for educational research and for teaching practices within higher education.
\end{abstract}

The article is frontline in the sense that it aims at developing a theoretical conception of situated reflection by combining cultural historical activity theory with pragmatism and theories of situated learning. The novelty of the article is to consider levels of human activity as levels of reflection and to introduce the distinction between theoretical and empirical reflection. Further, the article provides arguments that awareness of objects and instruments of human activity forms the basis of reflective processes. Finally, the article explains how reflection can connect levels of human activity and learning.

Keywords: Reflection; Mediation; Situated learning; Cultural historical activity theory; Pragmatism 


\section{Introduction}

The article addresses the question: how can we conceptualise processes of reflection? The objective of the article is to contribute to a theoretical understanding of reflection that can be used in empirical studies of reflective activities, and that can be utilised for development of educational practices, specifically within higher education. The aim is to develop a framework that can aid teachers in facilitating, identifying and evaluating activities of reflection of higher education students. More specifically, the article develops a concept of reflection that combines theories of situated learning with pragmatism and cultural historical activity theory.

Starting from a situated learning approach, processes of reflection are positioned in direct relation to the immediate activities of the learner. Most notably, Schön's $(1983 ; 1987)$ concepts of knowing-in-action and reflection-in-action situate learning, knowledge and reflection in practice and connects them directly to ongoing activities. Also, Suchman's $(1987 ; 1996)$ concept of situated actions connects knowledge to the very processes of performing activities. Similar views are found in Lave \& Wenger (1991), Wenger (1998), Billet (1996; 2001) and Semin \& Smith (2013) who connect learning to social practices, and also argue that knowledge is bound up in the context and processes of practices. Within a frame of these theories, this article raises the question of how to understand reflective processes situated in practice. The aim of the article is to further develop this position that examines reflection as an active part of an ongoing practice.

Schön's (1987) concept of reflection-in-action forms a basis for the theoretical development of a concept of reflection. However, Schön (ibid) does not clarify how reflection takes place, and what the prerequisites are for reflection. How does reflection connect to the ongoing activities of a student, and what makes an activity reflective? In order to address these questions and further develop a situated concept of reflection, the article will combine the pragmatism of Dewey's $(1916 ; 1958)$ concept of reflective experience and Schön's (1987) conception of reflection-in-action with an activity theoretical approach to learning activities (Leontev 1978; Engeström 2014).

\section{The situated nature of learning}

Within the research literature on situated learning and situated cognition, different dimensions of the situated nature of learning are described (Roth \& Jornet 2013; Compton 2013). At least three different dimensions can be identified within the literature. Firstly, learning is situated within sociocultural contexts, which emphasises that learning is rooted in practices that have a cultural and historical origin (Wertsch 1998; Engeström 2014; 1999; Engeström \& Sannino 2010; 2012; Leontev 1978). Secondly, a body of literature situates learning within local settings of social practices (Lave \& Wenger 1991; Wenger 1998; Hutchins 1995;1996; Billet 2001; Semin \& Smith 2013). Thirdly, learning is also conceived as situated within immediate activities meaning that knowledge exists within the very processes of acting (Schön 1987; Suchman 1987; Fors, Bäckström \& Pink 2013).

Of the first conception of the nature of situated learning, Wertsch $(1998 ; 109)$ writes that "[...] virtually all human action, be it on the individual or social interactional plane, is socioculturally situated [...].". Leontev (1978) and Engeström $(2014 ; 1999)$ position activities of the individual within a collective activity. Engeström (1999) brings forth the argument that human activity is culturally and historically situated, which means that learning is a local instance that inherits from practices situated in a culture and with a historical development.

The understanding that learning is situated in local settings of social practices has most notably been advocated by Lave \& Wenger (1991) and Wenger (1998) who connect learning to communities of practice. They provide a different dimension of the situated nature of learning than Engeström $(2014 ; 1999)$ and Leontev (1978), because Lave \& Wenger (1991) situate learning within local practices as they unfold and develop. A study in Billet (2001) also shows that expertise of practitioners is bound up in the activities unfolding in local practices. Both Wenger (1998) and Billet (2001) argue that knowledge is developed within these practices and cannot be extracted from the setting or processes of the practices. Also, this dimension highlights the socially situated nature of learning; learning stems from social relations and negotiations between individuals within a practice (Semin \& Smith 2013; Wenger 1998). 
Finally, the view that learning is situated in immediate processes of acting has mainly been influenced by Dewey's $(1916 ; 1958)$ concept of experience. Schön $(1983 ; 1987)$ draws on the approach of Dewey in developing the concepts of knowing-in-action and reflection-in-action. These concepts directly situate knowledge and reflection in practice and connect them to ongoing activities. Further, Suchman's (1987; 1996) concept of situated actions connects knowledge to the very processes of performing activities. A more recent concept of sensory-emplaced learning by Fors, Bäckström \& Pink (2013) continue this line of thinking and expands it by emphasising the embodied aspect of situated learning.

While theories of situated learning are well-developed, a concept of situated reflection lacks theoretical foundation. The aim of this article is to develop a conception of reflection that encompasses the different dimensions of situated learning. The common denominator for the different dimensions is the close connection between human activity and learning.

\section{Situating Learning within Levels of Human Activity}

Cultural historical activity theory (CHAT) emphasises human activity as the central aspect of knowing and learning (Vygotsky 1978; Leontev 1978; Leontyev 1981). The fundamental premise of CHAT is that the higher psychological functions of the mind have a sociocultural origin (Vygotsky 1978; Wertsch 1994). Leontev's distinction between levels of human activity and learning and Engeström's continuation of this distinction (Leontev 1978; Engeström 2014) will provide the theoretical foundation of the framework presented in this article. Following Leontev (1978), human activity fundamentally relates to the concepts of activities, objects and instruments, which describe the levels of human activity. Human activity is objectoriented, meaning that activities are directed at objects (or objectives) in the world. Leontev (ibid) argues that an activity is directed towards a motive, actions towards goals and operations towards conditions. For example, a human activity could be museum activity with a motive of preserving and disseminating cultural heritage or maintaining a national identity (human activity can have a composite motive). Within this motive exists a range of goals of the individual staff members, including setting up exhibitions, cataloguing artefacts, and doing guided tours. Finally, operations are the specific visible "movements" such as moving around artefacts, writing texts, labelling objects, etc. In order to achieve the object of the activity, humans mediate their activity with instruments. Engeström (2014) completes the structure of activity with his distinction between levels of instruments (Figure 1); motives are mediated by a methodology, goals with models and operations with tools. A methodology for a museum could be communication theory, information theory or educational theory, models include principles for organising and setting up exhibitions and systems for cataloguing, and tools could be exhibition cases, exhibited artefacts, posters, etc.

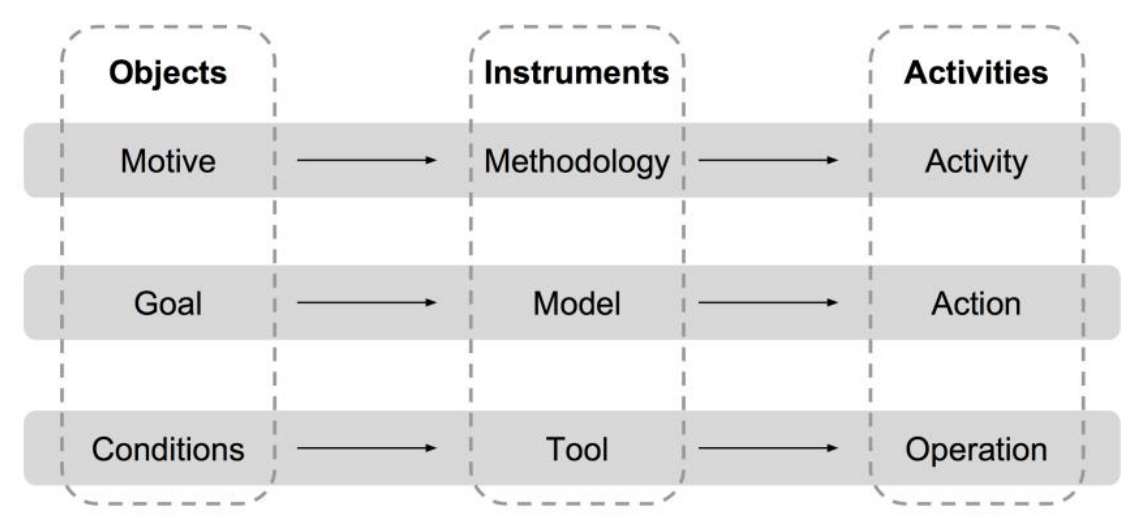

Figure 1. Levels of human activity.

Inspired by Bateson (1972), Engeström (2014) makes a classification of three levels of learning. Based on the theory of logical types, Bateson (1972) defines five levels of learning; Learning 0, I, II, III and IV, where learning 0 is a response to a situation, and Learning IV would imply a combination of phylogenesis and ontogenesis (Bateson 1972; p. 293). Bateson defines learning on a higher level as a change in the process of 
learning at a lower level. Lower level learning is a member of the higher level. For example, learning I is a member or an instance of the type Learning II, which classifies Learning I. Within Learning 0, the individual adapts his/her behavior according to stimuli of a situation. Learning I is a classification of the stimuli of a situation and entails a change in the rules for Learning 0 . Learning II is a classification of a pattern within the situation. This pattern can classify other situations of the same type, thus changing Learning I. According to Bateson, Learning II is learning to learn.

Engeström uses this classification from Bateson to define the use of instruments for operations, actions and an activity, respectively, as different levels of learning; i.e. Learning I, II and III. Learning I involves a change in or development of physical operations - that is, movements - of an individual, and it involves use or development of concrete tools. Learning II is development of actions that can attain a goal of an individual. Learning II, then, involves development of models in the form of concepts, principles or ways of working. In Engeström's conception of the levels of learning, Learning II must also result in Learning I, since an action is not manifested, before it is performed through operations with tools. Finally, Learning III is development of new forms of human activity, which include development of methodologies such as theories or policies for the activity. Learning I is always based on a change in conditions; that is, the physical materials and surroundings. Learning II begins with a new goal for human action, and finally, Learning III can only take place, if a new motive for human activity emerges. An historical example of Learning III is the emergence of a motive for public child care that has resulted in day care institutions.

The distinction between three dimensions (objects, instruments and activities) and three levels of human activity (motive, goal, conditions, etc.) provides the framework for developing a sociocultural framework for learning and reflection. According to Engeström (2014), an activity or action is not developed until a given methodology or model has affected the development of new operations and tools. This means that Learning III requires development of new actions, operations and tools (i.e. Learning I). Learning II and III without Learning I will be abstract or theoretical and have no impact on human activity.

This article will extend this sociocultural understanding by developing a concept of reflective mediation that aims at describing the processes on each level and explain the relations between the levels. Consequently, the framework splits Engeström's levels of learning into a range of different processes of learning and reflection. This means, for instance, that Learning III is accomplished through (sub)processes of mediation and reflection on all three levels.

A central question in understanding the processes of learning within an activity theoretical conception is: what are the relations between the levels of activity illustrated in Figure 1? And, more specifically, how does the individual make a connection between the levels? According to Leontev (1978), the levels cannot be separated, since an activity is carried out through actions and operations, while operations serve actions which again serve an activity. In that sense, there is an interdependence between the three levels, which cannot exist in isolation. Engeström (2014) also argues for this interdependence between the levels of human activity; he states that models are developed on the basis of a methodology, and tools are developed on the basis of a model. This means that an operation, for instance, is somehow related to an action. Below, the article will present a way of understanding, how the levels of human activity are related.

\section{Awareness of Objects and Instruments as a Basis for Reflection}

Using Wartofsky's (1979) concept of model, it can be argued that the levels of human activity can be viewed as levels of awareness of the individual, and that this awareness is a prerequisite for reflection. Wartofsky (ibid) defines models as cognitive artefacts that are "representations to ourselves of what we do, of what we want, and of what we hope for" (1979; xv). Wartofsky (ibid) describes models as "modes of action" that both embody human purpose and instruments for carrying out purposes. This means that models are parallel to and encompass both objects and instruments of human activity (Figure 1). Following Wartofsky, models can be viewed as the individual's awareness or representation of instruments, and Wartofsky (1979; xviii) directly connects models and representational artefacts with human consciousness. The key in Wartofsky's understanding of models in relation to reflection is that human consciousness uses models to present itself with its own objects. Thus, the instruments and objects of human activity can be viewed as something that individuals can be consciously aware of. 
As Leontev (1978) states, there is no obvious relationship between the levels of human activity. Leontev (ibid) writes: "Let us assume that the goal remains the same; conditions in which it is assigned, however, change. Then it is specifically and only the operational content of the action that changes" (no page number). This means that on one hand, a sequence of operations constitutes an action, but on the other hand, an action is a form of generalisation of the different sequences of operations that are able to accomplish the goal of the action. In other words, although there is an interdependence between the levels of human activity, they also have an existence - at least for the individual - on their own. A goal, for instance, can have a conscious representation for the individual in itself without an awareness of the overall motive. Consequently, there is no direct link between the three levels (in Figure 1). The objects and instruments on each level represent independent units and concepts that the individual might be aware of. A methodology can be defined as a generalisation of all the models that can be used to carry out the activity. A model can be defined as a generalisation of all the tools that can be used to carry out the action. For example, a pedagogical model of collaborative learning can result in different specific pedagogical methods such as peer-feedback, group work, project work, etc. This is the argument for viewing the levels of human activity as different levels of awareness.

It is possible to be aware of objects and instruments on all three levels of activity. For example, an individual can perform practical operations such as playing the keys on a piano. The individual can develop operational expertise in playing fast and putting the right pressure on the keys without being aware of a goal of the action which the operations serve, such as expressing oneself or creating enjoyment. An individual's awareness of objects and instruments on a higher level (models and methodology) makes it possible to consider a larger aspect of the activity and therefore to develop the activity more fundamentally. As Engeström (2014) writes, a methodology can develop new forms of actions, and models can be used to develop new forms of operations. Similarly, awareness of higher levels of human activity can result in a more fundamental understanding of the activity. For instance, the individual who plays the keys on a piano, uses the music to express feelings, and understands the role of music in society, understands music rooted in all three levels.

Awareness of a goal or motive means that the individual can understand tools and operations on a higher level. The highest level of learning - what Engeström (2014) calls Learning III - can according to Engeström (ibid) only be performed by a collective and not by the individual. However, the individual can be aware of motives and methodologies of an overall collective activity and use them to perform individual actions. As an example, a doctor is unable to perform all activities of a heart surgery, but he/she may be aware of the activities of the other doctors and nurses and understand the entire activity of the surgical procedure.

\section{Empirical and theoretical reflection}

Wartofsky (1968) argues that the individual's awareness of a conceptual construction of an artefact is what makes reflection possible: "[T]he possibility of reflective examination of the relations between ends and means arises only with the development of a conceptual representation of action" (ibid; 37-38). Reflective examination of relations between ends and means is equivalent to reflection of relations between activities, objects and instruments. Because there is not direct relation between the levels of human activity, objects and instruments on a lower level of human activity cannot be derived from objects and instruments on a higher level. On the other hand, an instrument on a higher level cannot prescribe concrete solutions on a lower level of activity (Leontyev 1981). However, an individual can evaluate whether or not, for instance, a specific operation supports the goal of an action. The individual's awareness of a goal can be used to evaluate operations necessary to perform the action. Based on this, in this article, reflection is defined as an evaluation of the consequences of activities in relation to an object or an instrument on a higher level of activity.

This implies that there are two kinds of reflection. One form of reflection is evaluation in relation to an object on a higher level of activity, whereas the other form is evaluation in relation to an instrument on a higher level of activity. I term the first kind empirical reflection and the second kind theoretical reflection. This distinction follows Vygotsky's (1986) distinction between spontaneous, everyday concepts and scientific concepts, and Davydov's (1999) development of Vygotsky's concepts in his distinction between empirical and theoretical thinking. Dewey (1997) makes a similar distinction between empirical and scientific thinking. According to both Davydov (1999) and Dewey (1997) empirical thinking is based on common sense and concrete observations of the given situation. This corresponds to the individual's awareness of objects, which 
relate to the practical and empirical situation of the individual. On the other hand, according to Dewey (1997) theoretical thinking involves an analysis of the situation. This corresponds to an awareness of instruments, which enable the individual to think beyond the conditions of the concrete, empirical situation.

Empirical reflection is based on the individual's awareness of objects of human activity. An object constitutes the underlying purpose or objective of human activity, and it forms the basis of the very existence of human activity (Leontev 1978). But for the individual, the awareness of an object can be a conception that guides his/her activities. Billet (2001) uses the term goal-directed and Dewey $(1916 ; 1997)$ uses the term endin-view to describe the directed nature of human activity. In the words of Dewey (1916), activities have an aim or purpose, and to act with an end-in-view means that humans have a conception or awareness of the result of the actions. This imagined idea of the outcome makes empirical reflection possible. When humans perform an operation, they can reflect upon the consequences of the operation in relation to the object of the action.

Theoretical reflection is based on the individual's awareness of instruments of human activity. According to Wartofsky (1979) an instrument is at the same time a concrete thing and a conceptual construction which describes a generalisation of future activities. This explains how to understand the relationship between practical, empirical knowledge and conceptual, theoretical knowledge. Theoretical concepts are invested with meaning from human activity, because they are used for purposeful, object-oriented activity. This means that theoretical knowledge is not detached from human activity, but is rather relative to the objects of the individual. As Brown, Collins \& Duguid (1989) argue, concepts and theories are similar to tools in the sense that they are acquired through use. This means that a concrete tool employed to mediate physical conditions has a theoretical dimension in the same way that a concept is utilised to mediate a goal. In other words, using a chair for "resting" has a similarity with using a constructivist model to "plan a university course", or using concepts from rhetoric to "analyse a speech". The theoretical dimension of a tool is not confined to the given physical thing used as a tool, because other things could potentially be used as the same tool to reach the same object - for instance, using a stump of tree for resting, using an action learning approach in course planning, or applying a narrative approach to speech analysis. Thus, a physical thing is not conceptualised by the individual as a specific and concrete entity, but instead as a tool with a general "use"; for instance, "use of a chair for resting" is a theoretical dimension of a tool. Further, one and the same physical thing can potentially be used as different tools. The chair can be used for sitting or to stand on when changing a light bulb, thus holding different theoretical dimensions.

The levels of awareness as described above take the individual as a point of departure. However, it is important not to dismiss the social nature of human activity (Semin \& Smith 2013). Ultimately, Leontev (1979) and Wartofsky (1979) argue that human activity is collective and involves social interaction. The individual's awareness of the different levels does not explain the role of social interaction for learning. When the individual is directed at a motive, learning also entails the awareness of the actions of other individuals. The key to the social dimension underlying all learning is the motive behind human activity. A motive stands above the individual in the sense that it constitutes a motive for the collective activity of humans (Leontev 1978). Understanding a motive requires the individual's understanding of his/her relations to other individuals performing actions within the activity. Consequently, reflection in relation to a motive or a methodology involves reflection on one's own actions in relation to actions of other individuals.

\section{Processes of Reflective Mediation}

The concept of object-oriented mediated activities is key to understand learning processes within CHAT, and the concept has been treated thoroughly by many authors (Vygotsky 1978; Leontev 1978; Engeström, 2014; Billet 1996). However, the very processes involved in mediated activities are not unfolded within CHAT. Engeström (2009) describes sequences of learning actions on a long term, but not situated, immediate processes. In order to explain the processes of learning and reflection, the article will draw on social theories of learning that argue for the importance of studying and understanding processes of human activities to understand learning (Suchman 1987;1996; Schön 1987; Lave \& Wenger 1991; Lave 1996; Chaiklin \& Lave 1996; Salomon 1993).

With the concept of situated action, Suchman $(1987 ; 1996)$ argues that human activity is not based on static concepts and preconceived plans that are applied to different situations, but that human activity adapts 
to the specific circumstances, and unfolds in the very course of action. Lave \& Wenger (1991; Lave 1996) have continued this line of thinking in their concept of situated learning, which emphasises that "Learning is an integral aspect of activity in and with the world at all times" (Lave 1996; 8). Similar to this, Salomon \& Perkins (1998) describe learning as a "highly situated activity of participation". Schön (1987) relates the situated nature of human activity to knowledge and uses the term knowing-in-action to describe that knowledge relates to actions and cannot be separated from them. Knowledge should be understood as knowing, which is a process related to situated activities. Related to the levels of human activity (Figure 1) this means that instruments in relation to objects are not static conceptions but exist within the very processes of mediation.

In order to conceptualise processes of learning and reflection, the article draws on Dewey's (1916; 1958) concept of experience, which describes processes involved in mediated activities. The conceptualisation is also inspired by Engeström and Sannino (2012) who describe seven actions of expansive learning: questioning, analysing, modelling, examining the developed model, implementing the model, reflecting and consolidating (a new form of practice). Dewey $(1916 ; 1958)$ uses the term reflective experience to describe learning from experience. He divides reflective experience into a number of processes: (i) perplexity, confusion or doubt, (ii) a conjectural anticipation, (iii) careful survey or examination, (iv) elaboration of the tentative hypothesis, and (v) a plan of action and doing something (Dewey 1916; 150). These processes can be used to supplement activity theory. Together, Dewey's (i) and (ii) can be translated into the conscious formation of an object that directs the activities of the individual. Dewey's (iii), (iv) and (v) can be used to clarify sub processes of mediation. In the third process, Dewey highlights an initial process of examining the opportunities of the situation, including examination of tools that might help reach the object of the activities. According to Dewey, the result of this examination is a construction of a hypothesis or an idea for doing (iv). Finally, (v) is the actual doing, the performing of activities. From the concept of object-oriented mediated activity, reflection as defined above, and Dewey's reflective experience, it is possible to describe the following elements or processes of learning: 1) Object, 2) Examination, 3) Construction, 4) Activities, 5) Judgment, 6) Reflection. Figure 2 illustrates the processes of learning.

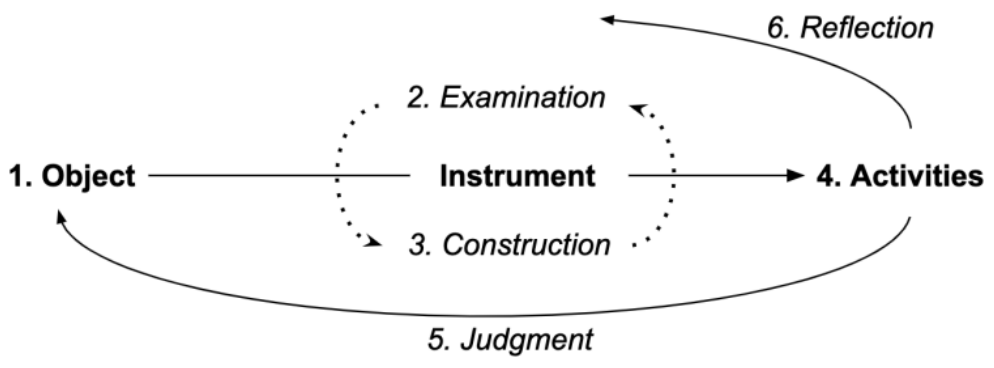

Figure 2. Process of learning (and reflection).

The basis for learning is an object or aim of the individual's activity. An object can be on either of the three levels of human activity. This corresponds with Dewey's (i) and (ii). Further, following Dewey (iii), the individual will conduct processes of examination of instruments in order to construct an idea or what Dewey (iv) terms an hypothesis of which instruments to use to reach the object. Then, the individual acts upon the hypothesis (v), meaning that he/she mediates the object by performing actions.

To these processes described by Dewey, this article will add judging of an action in relation to an object (on the same level of activity). Judging is seen as part of learning, but not reflection. To learn, the individual must know, if the action was "successful" (i.e. mediated the object). Thus, mediation requires an awareness of the object and a judgment of consequences of an action in relation to this object. Otherwise it is blind action, and learning is not possible. If the instrument does not mediate the object, the individual can repeat the processes and mediate again using other tools or using tools differently. This is a learning process and is not considered reflection in this article. Together, elements 1 through 5 describe processes of mediation of objects, i.e. a learning process. 
This article will add the process of reflection to the understanding of learning processes. The individual can - potentially - reflect on the consequences of the activities in relation to an object or instrument on a higher level of awareness. The fifth process is judgment in relation to the object on the same level of activity, whereas reflection is defined as evaluation on a higher level of awareness. In other words, judgment relates to the very immediate activities that the individual is involved in. For example, within an activity of film production, an editor could continuously judge the flow and precision of the scenes. Reflection would involve evaluation of the results in relation to a specific genre, a desired atmosphere, etc. Following activity theory, an action can have multiple goals (and similarly an activity can have more than one motive). If, for instance, an action has more than one goal, the individual can then potentially reflect on the different goals of the action; multiple goals would mean that reflection should also be multiple.

Taken together, the processes of learning and reflection form what I will term reflective mediation, which aims at describing both situated learning and reflection. The concept of reflective mediation will be developed in this article to describe processes of learning on each of the three levels of human activity, and processes of learning that cross the levels (cf. figure 1). The latter entails processes of reflection. The processes of reflective mediation can be described within three fundamental forms of learning:

1. mediation of objects with instruments,

2. empirical reflection on consequences in relation to objects on a higher level of activity, and

3. theoretical reflection on consequences in relation to instruments on a higher level of activity

Each of the three forms can exist on the different levels of human activity. They are unfolded below.

\section{A Framework for Learning and Reflection}

Based on the above definition of processes of learning and reflection, it is now possible to develop a theoretical framework for learning and reflection. From the elements of learning (illustrated in Figure 2), mediation is defined as use and judgment of an instrument in relation to an object of an activity. As illustrated in Figure 3, mediation can exist on three levels; methodologies are used to mediate a motive, models to mediate goals, and tools to mediate conditions. However, methodologies and models are only theoretical mediations or "thought experiments", since they do not influence practice. Such mediations would typically exist within higher education in the form of project reports or written assignments. To change practice, however, the instruments must be manifested in tools and operations.
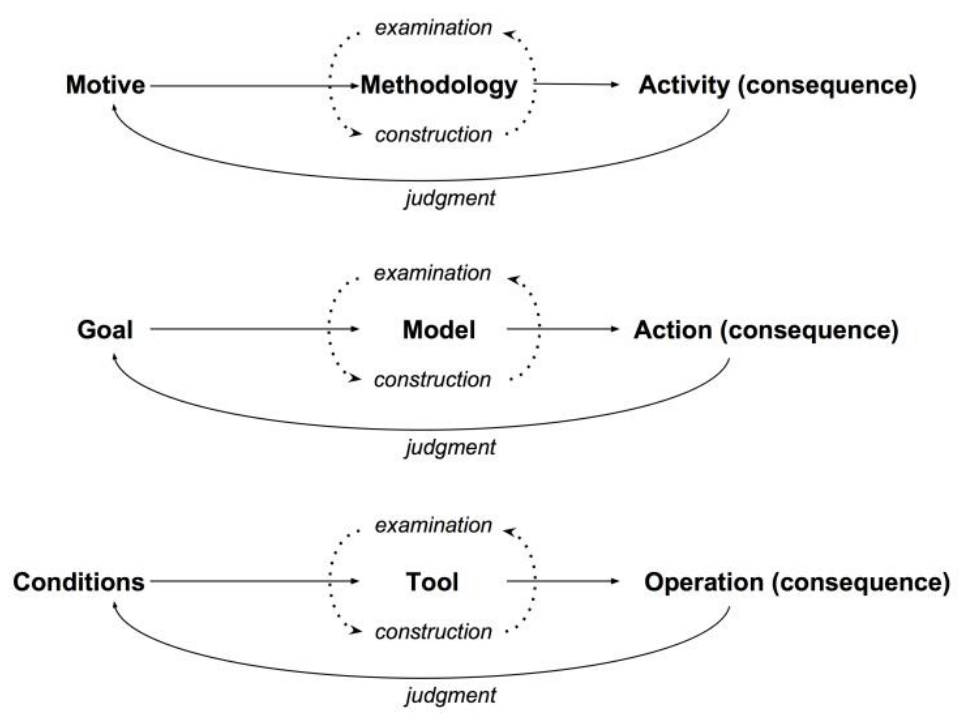
Figure 3. Mediation exists on three levels: 1) mediated operation (bottom), 2) mediated action (middle) and 3) mediated activity (top).

Mediation results in an understanding of a given instrument in relation to its object. This constitutes learning in its own respect. An example within higher education could be students' utilisation of an analytical method (a model) such as conversational analysis to interpret (action) a dialogue. However, adding reflective processes to mediation would result in a deeper understanding of the given instrument. Reflection adds to the understanding of the mediation process by connecting it to another level, and thus widens the understanding. Reflective mediation describes the process in which learning occurs with the awareness of a higher level of activity. The distinction above between empirical and theoretical reflection implies that there are two forms of reflective mediation processes. Empirical reflective mediation is reflection on consequences in relation to an object on a higher level of activity (Figure 4), whereas theoretical reflective mediation is reflection on consequences in relation to an instrument on a higher level of activity (Figure 5).
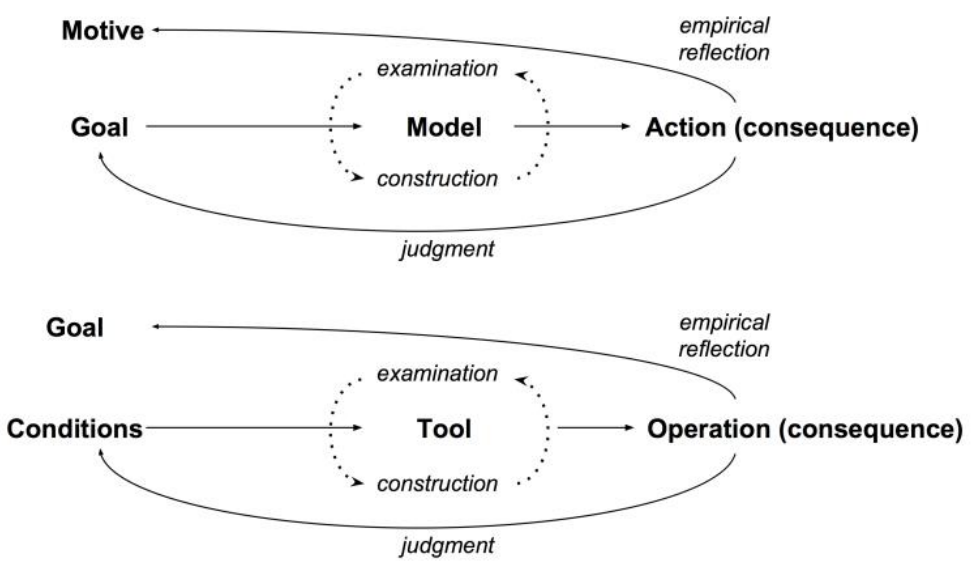

Figure 4. Empirical reflective mediation exists on two levels: 1) empirical reflective operation (bottom) and 2) empirical reflective action (top).

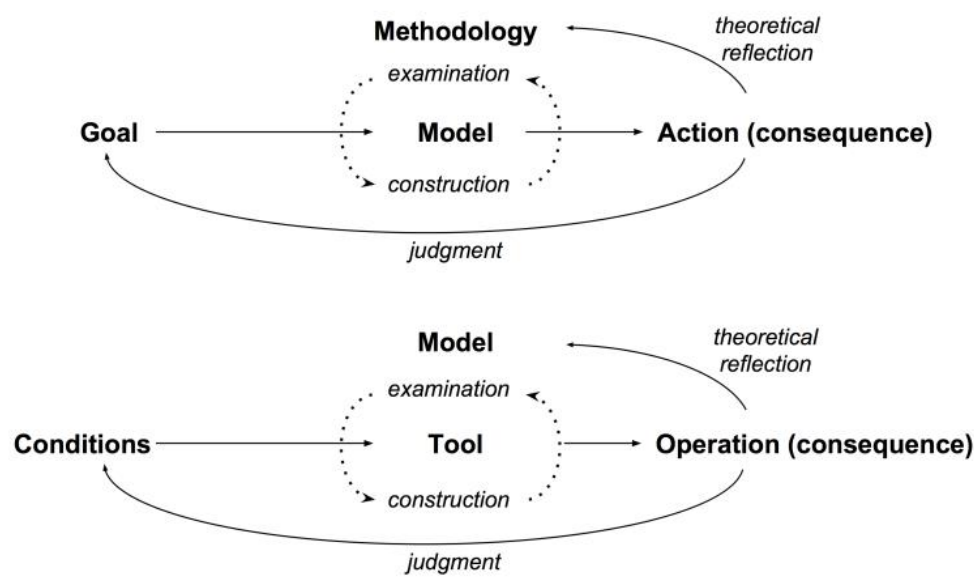

Figure 5. Theoretical reflective mediation exists on two levels: 1) theoretical reflective operation (bottom) and 2) theoretical reflective action (top).

Based on the distinction between mediation, empirical reflective mediation and theoretical reflective mediation, the developed sociocultural framework contains seven different categories of learning and reflection. Below, the seven categories are related to Engeström's three levels of learning:

\section{Learning I}


Mediated operation

Empirical reflective operation

Theoretical reflective operation

\section{Learning II}

Mediated action

Empirical reflective action

Theoretical reflective action

\section{Learning III}

\section{Mediated activity}

Each of these seven categories can be characterised as processes of learning in their own respect. Mediation and reflective mediation in themselves imply learning, and each category of learning carries an independent understanding of a certain aspect of the activity. Ideally, however, learning involves all levels and categories of learning and reflection; meaning that the levels of human activity are connected for the individual.

\section{Implications for Teaching Methods}

This section will discuss how the theoretical framework can be used to support reflection within higher education teaching. Based on the framework, an educational practice for reflection should aim at supporting the students' connections between all levels of an activity. There is no hierarchy in the levels that ranks the importance or value of each of the levels, and there is no progression from one level to another. Thus, a central question in developing teaching methods is, which categories within the framework come first, and how teaching can be organised to support mediation and reflective mediation that covers the entire framework.

Since a motive is the foundation of human activity, this would be an obvious starting point. However, the activity mediating the motive is a collective activity of humans (Leontev 1978), which means that an individual cannot perform an activity him/herself. In that sense, the motive and activity cannot form the starting point for the individual's learning. As argued above, an individual can, however, be aware of the overall motive of the collective activity. This suggests that the individual as a starting point should be directed at a goal in order to perform an action. The argument for goals as the starting point for learning is that goals can connect to the life of the student.

This is in line with the approach of Dewey (1916), who argues that the training of skills should never be detached from a purpose. An object should present itself as a problem for the student in order to hold a potential for learning. The goal should take the form of what can be termed an empirical problem. At the same time, the individual should ideally be aware of an overall motive of the action. In that sense, although mediation and reflective mediation on each level of awareness constitute processes of learning in their own respect, learning activities should always be grounded in a motive and directed at a goal. Further, learning should ideally point towards operations in practice.

An example could be taken from teaching a university communication studies course. Starting points for a course within communication studies could be a goal (empirical problem) of the students to either develop a communication strategy for a company, organise a political campaign, organise a public service information campaign, or create an advertisement for a commercial product. Once engaged in an empirical problem with the awareness of a goal, the students can perform actions and operations. In the example from communication studies, the teacher should present students with instruments for achieving the objects. Instruments for operations and actions of the students will differ depending on which of the outlined goals students are working on. For instance, whereas developing a communication strategy would involve models of branding and organisational image, creating an advertisement includes models for marketing and target groups. Operations of students could involve producing a radio or TV commercial, which would involve writing manuscripts, 
recording, editing, etc. The empirical problem of creating an advertisement for a product can on the one hand provide the opportunity to perform concrete operations in practice. On the other hand, the empirical problem makes it possible to reflect in relation to motives and methodologies. A motive for developing an advertisement for a company might be creating attention and reaching a large audience, whereas the motive of an information campaign could be to communicate a certain message to a specific target group. Both of these objects of student activities could result in production of TV ads, but if students reflect empirically on their ads in relation to the motives, the ads will be very different.

Teachers should support students in theoretical reflection related to their object-oriented activities. Although the motives of the student activities are different, the methodologies can be the same in the form of communication theories. Students might reflect on their communication strategy or advertisement in relation to theories from writers such as Shannon \& Weaver, Jakobson, Bakhtin, etc. Thus, the role of communication theory would be as an instrument of theoretical reflection within students' work on an empirical problem.

Since concepts and theories are dominant within academic contexts in higher education, the theoretical framework of reflective mediation has implications for educational practice of higher education. The implications of the presented framework would be not to teach concepts and theories isolated from an empirical problem. The framework calls for employing concepts and theories as instruments related to object-oriented activities. As a consequence, models and methodologies become secondary to the object of student activities, but on the other hand they are key to theoretical reflection.

Following the approach of the framework, reflection in educational practice is not a matter of students viewing their own work from a distance, but is rather a matter of embedding reflective processes in their situated activities. To support this as a teacher requires that students are made aware of concepts and theories that they can consciously employ for reflection. To put it in other words, students need tools and objects for reflection, and cannot be asked to just "reflect" on their work. A central point taken from the situated approach of this article is that although reflective processes are key in understanding a given subject area, they are very difficult to assess based on a final product or assignment - for instance, the final advertisement. It is not possible to track down the reflective processes of students. They must be identified within the processes. This calls for making both students and teachers aware of the nature and the importance of such situated processes of judgment and reflection.

\section{Conclusion}

The presented framework of seven categories of learning and reflection points towards certain focus areas within teaching methods. However, it is necessary to conduct empirical studies of learning activities to learn more about reflective processes. The presented framework has implications for such future research. Research within situated reflection calls for studies that can identify very specific processes of students' activities. Such research requires observations of students in action. Situated reflection cannot be identified through interviews that look back on activities. Students might not be aware of their reflective processes, and thus they must be identified within the situations. Further, in order to discover reflective processes, it is necessary to engage in dialogue with the students about their objectives and considerations within their situated activities.

Further, the framework of this article provides analytical concepts that can guide empirical studies on situated reflective activities. Based on the framework, empirical studies on reflective activities could employ the concepts of object, examination and construction, instrument, judgment and reflection to analyse student activities through observational studies. The concept of object can be used to identify the directed nature of students' activities: Are students aware of an object, aim or purpose of their activities in their studies, and do they understand what that object, aim or purpose is? A challenge of such studies is that it requires asking students questions during their reflective activities, or asking them to "think aloud".

Empirical studies could also focus on identifying examination and construction of instruments in student activities: Are students actively involved in examining instruments, tools, concepts and theories with the aim of using them to reach the object? Such processes would involve students' active engagement with the subject matter, but with an intention of using them for an end. When looking for processes of judgment, 
empirical studies could examine whether students have a conscious awareness of the object, end or aim of their activities and whether they use this awareness to judge their own activities. Finally, studying reflection involves an examination of whether objects (in the form of empirical goals and motives) and instruments (in the form of conceptual and theoretical models and methodologies) are present in student activities. For instance, are communication theories present in students' situated work on creating an advertisement? Secondly, are these objects and instruments used actively in students work for empirical and/or theoretical reflection on their activities; do concepts from communication theory influence the advertisement? The main challenge of such research is to make the situated reflective activities visible. Examination and construction may be visible in some cases, whereas judgment and reflection are often unspoken. Studying reflection in group work may be a way forward, because discussions between students may make visible their joint reflection.

In conclusion, the framework can be used as a basis for future studies that examine whether and how students are able to reflect, empirically and theoretically.

\section{Keypoints}

- Reflection is not only a matter of students viewing their work from a distance, but also a matter of embedding reflection in situated activities.

- Reflection requires tools (concepts and theories) and objects (aims and purposes) that students can consciously employ for reflection.

- Concepts, models and theories should not be taught in isolation, but should be employed as instruments related to students' object-oriented activity.

- Learning activities should ideally be directed at a goal, grounded in a motive, and point towards operations in practice.

- Concepts, models and theories become secondary to the object of student activities, but on the other hand they are key to theoretical reflection.

\section{References}

Bateson, G. (1972). Steps to an Ecology of Mind. The University of Chicago Press.

Billet, S. (1996). Situated Learning: Bridging Sociocultural and Cognitive Theorising, Learning and Instruction, Vol 6(3), pp. 263-280.

Billet, S. (2001). Knowing in practice: re-conceptualising vocational expertise, Learning and Instruction, 11 (2001), pp. 431-452.

Brown, J. S., Collins, A., \& Duguid, P. (1989). Situated Cognition and the Culture of Learning. Educational Researcher, Vol. 18(1), 32-42.

Chaiklin, Seth, \& Lave, Jean. (1996). Understanding practice. Perspectives on activity and context. Cambridge University Press.

Compton, P. (2013). Situated cognition and knowledge acquisition research, International Journal of HumanComputer Studies, Vol 71(2013), pp. 184-190.

Davydov, V. V. (1988). Problems of Developmental Teaching (Part I). Soviet Education, August.

Davydov, V. V. (1999). What is Real Learning Activity? In M. Hedegaard, \& J. Lompscher (Eds.), Learning Activity and Development (pp. 123-138). Aarhus University Press.

Dewey, J. (1916). Democracy and Education. The Free Press.

Dewey, J. (1938). Logic. The Theory of Inquiry. New York: Henry Holt and Company.

Dewey, J. (1958). Experience and nature. New York: Dover Publications.

Dewey, J. (1997). How we think. New York: Dover Publications.

Engeström, Y. (2014). Learning by expanding. An Activity-Theoretical Approach to Developmental Research. 2nd edition. Cambridge University Press December 2014.

Engeström, Y. (1999). Expansive visibilization of work: An activity-theoretical perspective. Computer Supported Cooperative Work (CSCW), 8(1), 63-93.

Engeström, Y. (2001). Expansive learning at work: Toward an activity theoretical reconceptualization. Journal of education and work, 14(1), 133-156. 
Engeström, Y., \& Sannino, A. (2010). Studies of expansive learning: Foundations, findings and future challenges. Educational Research Review, 5(1), 1-24.

Engeström, Y., \& Sannino, A. (2012). Whatever happened to process theories of learning? Learning, Culture and Social Interaction, 1 (1), $45-56$.

Fors, V., Bäckström, Å., \& Pink, S. (2013). Multisensory emplaced learning: Resituating situated learning in a moving world, Mind, Culture, and Activity, Vol 20(2), pp. 170-183.

Hutchins, Edwin (1995). Cognition in the Wild. London: The MIT Press.

Hutchins, Edwin (1996). Learning to navigate. I: Chaiklin, Seth and Lave, Jean (red.). Understanding practice. Perspectives on activity and context, p. 35-63. Cambridge University Press.

Lave, J. (1996). The practice of learning. In S. Chaiklin, \& J. Lave (Eds.), Understanding practice. Perspectives on activity and context (pp. 3-32). Cambridge University Press.

Lave, J., \& Wenger, E. (1991). Situated learning: Legitimate peripheral participation. Cambridge University Press.

Leontev, A. N. (1978). Activity, Consciousness, and Personality. Online: http://www.marxists.org/archive/leontev/works/1978/index.htm.

Leontyev, A. N. (1981). Problems of the development of the mind. Moscow: Progress Publishers.

Roth, W-M. \& Jornet, A. (2013). Situated cognition, WIREs Cogn Sci, Vol 4, pp. 463-478. doi: $10.1002 /$ wcs. 1242.

Salomon, G. (1993). Distributed cognitions. Cambridge University Press.

Salomon, G., \& Perkins, D. N. (1998). Individual and social aspects of learning. Review of research in education, 1-24.

Schön, D. A. (1983). The Reflective Practitioner. Ashgate.

Schön, D. A. (1987). Educating the Reflective Practitioner. San Francisco: Jossey-Bass.

Semin, G.R. \& E.R. (2013). Socially Situated Cognition, Social Cognition, Vol. 31(2), pp. 125-146.

Suchman, L. A. (1987). Plans and situated actions. Cambridge University Press.

Suchman, L. A., \& Trigg, R. H. (1996). Artificial intelligence as craftwork. In S. Chaiklin, \& J. Lave (Eds.), Understanding practice. Perspectives on activity and context (pp. 144-178). Cambridge University Press.

Vygotsky, L. S. (1978). Mind in Society. London: Harvard University Press.

Vygotsky, L. S. (1986). Though and Language. Cambridge: The MIT Press.

Wartofsky, M. W. (1968). Conceptual Foundations of Scientific Thought. New York: The Macmillan Company.

Wartofsky, M. W. (1979). Models: Representation and the Scientific Understanding. D. Reidel Publishing Company.

Wenger, E. (1998). Communities of Practice. Cambridge University Press.

Wertsch, J. V. (1994). The Primacy of Mediated Action in Sociocultural Studies. Mind, Culture, and Activity, Vol. 1(4), 202-208. 